\title{
¿Cómo cambian los conceptos acerca de la lectura y la escritura en la Facultad de Contaduría Pública de la UNAULA?
}

\author{
Gustavo Alberto Ruiz Rojas \\ Profesor e investigador Universidad Autónoma Latinoamericana - Colombia \\ Yuliana Arcila Arcila \\ Estudiante Universidad Autónoma Latinoamericana Colombia
}

\begin{abstract}
Resumen
Se efectúa una comparación entre las actitudes que los estudiantes de quinto año de contaduría pública de la Universidad Autónoma Latinoamericana tienen frente a la escritura y la lectura, con las de los estudiantes de primer semestre de contaduría pública de la Universidad Autónoma Latinoamericana. Se efectúa una contrastación con los resultados de un cuestionario abierto que indagaba acerca de prácticas y perspectivas sobre lectura y escritura. Con base en eso se establece una interpretación para definir si los estudiantes de quinto año mantienen creencias similares a los de primer semestre o si por el contrario éstas se han trasformado en un sentido que permita fortalecer la lectura y la escritura como estrategias de aprendizaje autónomo. Se encuentra que estas perspectivas no sólo no se han trasformado, sino que además se han agudizado.
\end{abstract}

\section{Palabras clave}

Actitudes; perspectivas; lectura; escritura; educación superior; contaduría pública.

\section{Abstract}

A comparison is made between the attitudes of fifth year student of Accounting at the University Autónoma Latinoamericana have before writing and reading, with the freshmen of Accounting at the University Autónoma Latinoameri-

Recibido: 17-08-2012-Versión final aceptada: 15-12-2012 
cana. It makes a contrasting with the results of an open questionnaire that asked about practices and perspectives of reading and writing. Based on an interpretation that is set to define whether fifth-year students hold beliefs similar to those of the first semester or whether on the contrary these have been transformed in a way that strengthens reading and writing as independent learning strategies. We find that these ideas have not only transformed, but have deepened.

\section{Key words}

Attitudes; concepts; literacy; higher education; public accountancy.

\section{Introducción}

Los problemas de lectura y escritura en la educación superior, lejos de ser un asunto que concierne exclusivamente a la formación básica o a los docentes de áreas de formación lingüística, es un problema de todos los involucrados en el proceso de formación.

En este artículo se aborda la descripción de unos de los directamente afectados por el problema: los estudiantes. A partir de una perspectiva socio-cultural de la lectura y la escritura, se afirma que estos procesos no son dominios individuales ni generalizables. Que el dominio de una lectura crítica y de una escritura productiva, va vinculado directamente a procesos de inclusión cultural, los cuales demandan el dominio de las formas como los discursos escritos circulan en el marco de las disciplinas.

De acuerdo con el grupo Didactex de la Universidad Complutense de Madrid, el enfoque sociocultural se basa en el reconocimiento de las Representaciones Sociales (RS) como factores que guían la acción $y$ potencian o dificultan el desarrollo de las habilidades de lectura y escritura. En ese sentido, tanto la escritura como la lectura, se insertan en el ámbito de unas formas de interacción cultural mediadas por un conjunto de creencias, actitudes, normas explícitas e implícitas, valores, formas y procesos de escritura, convenciones socioculturales, ideologías, que se convierten en significados sociales compartidos de los que el individuo hace uso e incorpora para establecer su relación con el mundo (2003, p. 77).

Según Paula Carlino, el concepto de Representación Social surge a partir de los estudios culturales francófonos. En otros contextos como 
¿Cómo cambian los conceptos acerca de la lectura y la escritura en la Facultad...

los anglófonos, se utiliza una gran diversidad de términos los cuales coinciden en interpretar estos sistemas de creencias como "intentos de comprender un sector del mundo social, de estabilizarlo y homogeneizarlo que tienen por efecto convertir en "normal" y en "natural" lo que no es sino una perspectiva entre otras posibles" (Carlino 2005, p. 1).

El estudio de las RS se convierte en una forma de describir aquellos marcos de referencia compartidos que potencian o limitan las posibilidades de fortalecer la lectura y la escritura en la educación superior. Cualquier intento de intervención en el campo de la lectura y la escritura en la educación superior, debe pasar por una reflexión acerca de las creencias, actitudes, prácticas y todos aquellos aspectos que configuren las RS en torno a la lectura y la escritura. Especialmente en el campo de la contaduría pública, ya que en este contexto se encuentra que dichos procesos no han encontrado una base cultural para su desarrollo. Como afirma John Jairo Cuevas, Investigador de la Universidad del Valle, "al no tener asiento la lectoescritura como dimensión relevante para la educación contable, cobra importancia una educación basada en procesos que privilegian más lo instrumental en quebranto de lo interpretativo" (Cuevas Mejía, 2009, p. 45).

Sin embargo, desde la Facultad de Contaduría Pública de la Universidad Autónoma Latinoamericana, se han realizado reflexiones en torno al sentido de la contabilidad y su dimensión social. En el contexto de las mismas, la lectura y la escritura han emergido como dominios esenciales tanto en el aprendizaje como en la investigación. Fruto de dichas reflexiones, surge el proyecto "Observatorio de lectura y escritura", cuyo propósito es desarrollar estrategias de intervención que fortalezcan la comprensión lectora y la composición escrita entre los estudiantes de contaduría pública.

Este tipo de intervenciones caen en el vacío de las buenas intenciones si no responden a una reflexión profunda en torno a las perspectivas sobre el papel que debe cumplir la lectura y la escritura en el campo de la formación de un contador público. Si bien se expresa de manera formal la necesidad de trasformar radicalmente las didácticas orales y transmisionistas por unas más investigativas, no existe claridad acerca del papel que cumplen la lectura y la escritura dentro del aprendizaje de las disciplinas.

Esta situación podría conducir a afianzar muchas de las RS que existen en torno al tema, lo cual en última instancia podría convertir tanto 
a la lectura como a la escritura en cargas adicionales, instrumentos de control y poder por parte del docente o un mero complemento del trabajo expositivo de las clases.

De allí que sea necesario indagar no sólo por aquellas RS que tienen los estudiantes de primer semestre de contaduría pública de la Universidad Autónoma Latinoamericana, como una forma de intervenir en ella a partir de las asignaturas del primer semestre de formación, sino que es necesario contrastarlas con los estudiantes de quinto año, para acercarse a una comparación en torno a la forma como estas actitudes se trasforman o mantienen durante el tiempo.

Como parte de las RS, las actitudes se convierten en una dimensión cognitiva de éstas. Se definen como la orientación favorable o desfavorable hacia una representación, con un carácter tridimensional compuesto por la afectividad (visión tradicional de las actitudes), los conocimientos, y las prácticas (Araya Umaña, 2002, p. 40). Aunque hacen parte de las RS no agotan el concepto, pues las actitudes se generan a partir de un estímulo en tanto las RS incluyen tanto el estímulo como la respuesta (Araya Umaña, 2002, p.45).

Optar por las actitudes implica una decisión metodológica que pretende describir la forma como algunas de las RS ya identificadas en el rastreo teórico, se convierten en estímulos favorables o desfavorables para el estudiante de contaduría pública de la Universidad Autónoma Latinoamericana. Se acepta que los resultados de este estudio no son concluyentes, sino que se convierten en un pretexto para formular nuevos interrogantes que permitan un seguimiento más profundo a las RS a estos estudiantes, especialmente en aquellos grupos de primer semestre que fueron objeto de la comparación.

Por tal motivo, este artículo responde a la siguiente pregunta ¿Las actitudes de los estudiantes de quinto año frente a la lectura y la escritu$\mathrm{ra}$, tienden a reafirmar algunas de las RS más perjudiciales, o presentan una trasformación positiva en ese sentido?

\section{Aspecto teórico}

Las actitudes como evidencia de las acciones indican una predisposición a actuar en un sentido u otro. No se convierten necesariamente en una evidencia inobjetable, pero sí ofrecen indicios acerca de 
¿Cómo cambian los conceptos acerca de la lectura y la escritura en la Facultad...

la posibilidad de orientar los comportamientos hacia unas tendencias favorables o desfavorables (Hernández Sampieri, Fernández Collado, \& Baptista Lucio, 2012).

En relación con las representaciones sociales (RS), surgen como respuesta a los estímulos derivados de ellas. No se convierten en una representación social, pero ofrecen indicios acerca de la presencia de éstas o no. Por tal razón, las actitudes se rastrean a partir del conocimiento teórico que se tiene acerca de algunas de las RS que mayor incidencia tienen en los problemas de lectura y escritura de la educación superior.

Para el caso de este artículo, se toman algunas de las que se encontraron en la indagación bibliográfica. Para ello, se toman en cuenta los aportes de la investigadora argentina Paula Carlino y los de algunos investigadores colombianos que han publicado sus avances en diferentes medios, tales como la revista Lenguaje de la Universidad del Valle, la revista Enunciación de la Universidad Distrital Francisco Javier de Caldas, La revista Forma y Función de la Universidad Nacional, la Revista de la Universidad Católica del Norte; así como las diferentes ponencias presentadas en los encuentros de la Red de Lectura y Escritura en la Educación Superior (REDLEES). Dicha integración se organiza a partir de dos apartados: las Representaciones Sociales sobre lectura y las Representaciones Sociales sobre escritura. Cabe anotar que los títulos se convierten en una decisión metodológica para agrupar investigaciones que han abordado creencias, actitudes, prácticas, imaginarios, opiniones, etc. Y han servido de base para preguntarse hasta qué punto las mismas se presentan en el contexto de la Facultad de Contaduría Pública de la Universidad Autónoma Latinoamericana ${ }^{1}$.

\section{Representaciones sociales sobre lectura}

Desde el punto de vista de la lectura, diversas investigaciones han encontrado una tendencia a percibir la lectura como dominio generalizable que el estudiante debe adquirir en su formación básica. Esto conduce a la

1 Estas representaciones se analizan con mayor profundidad en el artículo titulado: "acerca de las representaciones sociales en la lectura y escritura universitaria: implicaciones y posibilidades didácticas. El cual fue presentado para su revisión en la revista Lúmina". 
orfandad lectora, la cual se expresa en la tendencia a dejar solos a los estudiantes, y no ofrecerle las claves discursivas que les permitan integrarse con éxito a las nuevas demandas de la cultura disciplinar (Carlino, 2003, 2007; Nigro, 2006; Cadena Castillo, Narváez Cardona, \& Chacón, 2007; González Pinzón, 2007; May Carrascal, 2008; Bocca \& Vasconcelo, 2008)

Los hallazgos se sintetizan en las siguientes RS:

- La lectura como dominio generalizable: que desconoce que cada disciplina tiene sus propias prácticas discursivas

- La lectura como responsabilidad exclusiva del estudiante: que conduce a la orfandad de la lectura e interpreta las tareas de lectura como cargas adicionales y estrategias de control. Conducen a la idea errónea de que los textos fáciles contribuyen a un mayor aprendizaje

- La lectura como acto de relajación: que parangona lectura con literatura y deja de lado el dominio de estrategias necesarias para aprovechar la lectura académica

\section{Representaciones sociales sobre escritura}

Las percepciones culturales de formación lecto-escritora enfatizan sus esfuerzos en el fomento de la escritura como base para el desarrollo de la lectura. Por esta razón, hay prevalencia en el hallazgo de RS sobre escritura, las cuales se centran básicamente en el desconocimiento del valor que tiene la escritura como medio para construir conocimiento y en la noción de la escritura como producto y no como proceso (Calderón, 2001; Carlino, 2004, 2005a, 2005b, 2007; Nigro, 2006; Cadena Castillo, Narváez Cardona y Chacón 2007; Molano B. \& López, 2007; Bocca \& Vasconcelo, 2008; Lacon de Lucía \& Ortega de Hocevar, 2008; Vásquez, 2008; Padilla, Douglas de Sirgo, \& López, 2010; Polo Figueroa, Bustamante y Avendaño Pantoja).

De acuerdo con este rastreo, las principales RS sobre escritura son:

- La escritura como un acto de inspiración: ven al escritor como un privilegiado bendecido por los dioses y a la escritura como un dominio casi esotérico al cual pocos acceden. El producto de esto es la angustia ante la hoja en blanco y la postergación del 
¿Cómo cambian los conceptos acerca de la lectura y la escritura en la Facultad...

momento para escribir. Además se desdeñan algunas formas de escritura académica que son de gran utilidad.

- La escritura como tarea para el docente: no se escribe en condiciones auténticas de producción, lo cual convierte al docente en el único lector. De esta forma el texto se convierte en una traducción de conceptos sin propósito comunicativo, y sin tener en cuenta las características y necesidades comunicativas del lector. De igual forma, se enfatiza en el texto como producto y no hay un acompañamiento del docente en el proceso de escritura. No se interpreta la escritura como medio de aprendizaje.

- La escritura como reflejo del conocimiento: derivada de la anterior, en esta perspectiva no se escribe para aprender, se escribe para demostrar el conocimiento. La escritura se interpreta como simple traducción del saber, de acuerdo con una visión extractiva del conocimiento. El conocimiento está allí y hay que saberlo sacar y obviamente expresar de tal forma que no haya confusiones ni errores gramaticales. Esta RS afecta los procesos de revisión y reestructuración del texto a partir de la lectura entre pares.

Las tres representaciones descritas se afectan recíprocamente, formando un bucle que legitima ciertas prácticas escriturales en la educación superior. En el fondo de ellas subyace el desconocimiento de la escritura como un proceso de construcción permanente, sujeto a factores culturales, cognitivos, psicológicos y retóricos. Es indispensable entender que la escritura debe ser evaluada en función de sus propósitos comunicativos, desarrollar actividades de acompañamiento de la escritura mediante tutores de escritura en las áreas, formar a los docentes de las disciplinas en criterios textuales y retóricos para la orientación y evaluación de los textos de los estudiantes.

\section{Materiales y métodos}

\section{El estudio corresponde a un estudio descriptivo de diseño mixto}

Se toman dos grupos para contrastar: los estudiantes de primer semestre de contaduría pública matriculados en el primer semestre de 2011 y los estudiantes de quinto año de contaduría pública periodo 
2011. En el primer grupo la muestra es de 80 estudiantes, compuesta por dos grupos de la jornada diurna y dos de la nocturna. Para el segundo grupo la muestra es de 92 estudiantes, compuestos por un grupo de la jornada diurna y otro de la nocturna. Para efectos de este estudio no se discriminan jornadas, siendo el único criterio diferenciador el del semestre que cursen en la actualidad. Es decir, se efectúa una comparación entre los estudiantes que recién inician la universidad y aquellos que están finalizando sus carreras, tratando de encontrar entre estos dos extremos no sólo las diferencias sino también el cambio en los conceptos que se tienen acerca de la importancia de la lectura y la escritura en el proceso de formación académica.

Cuestionario 1 (C1): Primero, se les hace una encuesta acerca de lectura y escritura compuesta por 12 preguntas: 7 sobre lectura y 5 sobre escritura.

- ¿Para usted que significa leer?

- ¿Cuál es su experiencia con la lectura?

- Si a usted le preguntarán ¿qué clase de lector es usted, usted qué diría?

- ¿Qué lee habitualmente?

- ¿Para qué lee usted?

- ¿Cómo sabe usted que ha comprendido lo que lee?

- Si alguien le pidiera tres consejos para comprender mejor lo que lee, ¿qué consejos le brindaría?

- ¿Para usted qué es escribir bien?

- ¿A usted le agrada escribir? Explique sus razones.

- ¿Conoce usted las operaciones mentales que aplica al escribir?

- ¿Cuáles son las tareas que usted realiza cuando escribe?

- Si alguien le pidiera a usted tres consejos para escribir bien, ¿qué consejo le brindaría?

Cuestionario 2 (C2): Posteriormente, con base en los hallazgos teóricos, se diseñó una escala de actitudes con 17 ítems y 6 opciones de respuesta. Las opciones se escalan entre muy de acuerdo, de acuerdo, parcialmente de acuerdo, parcialmente en desacuerdo, en desacuerdo, y muy en desacuerdo. Se toma esta decisión con el fin de mitigar el efecto a responder en la tendencia media, respondiendo así a la mayor capacidad de 
¿Cómo cambian los conceptos acerca de la lectura y la escritura en la Facultad...

discriminación que se espera encontrar en los estudiantes de quinto año (Hernández Sampieri, Fernández Collado, \& Baptista Lucio, 2012).

A través de las 17 preguntas de la escala de actitudes (C2), se plantean cuestionamientos acerca de formación lecto-escritora que se ha adquirido en el bachillerato y aquella que se desprende de la educación universitaria, de la responsabilidad de estudiantes y docentes en estos procesos de formación y de la función que desempeña la escritura como expresión del conocimiento así como de las habilidades de los estudiantes para expresarlo a través de ella.

Se toman algunas de las respuestas de la escala (C2) y después se cruzan con los hallazgos encontrados en el análisis del cuestionario 1 (C1). El análisis de la escala es meramente descriptivo, observando tendencias e interpretándolas a partir de la teoría que se tiene. El cuestionario abierto fue sistematizado efectuando un conteo de las expresiones más recurrentes. Se trabaja como unidad de análisis las oraciones en algunos casos y en otros las palabras claves.

A partir de lo encontrado en el cruce entre ambos instrumentos se hace una interpretación que en ninguna forma pretende ser concluyente, pues son indicios que ameritan futuros trabajos de profundización.

Teniendo en cuenta estos aspectos, la encuesta es bastante ambiciosa al tratar de concluir aspectos importantes en una sola muestra y con un número tan reducido de preguntas, por lo cual se plantea la posibilidad de confirmar los datos obtenidos con muestreos posteriores.

\section{Resultados y discusión}

Resultados de la tabulación de datos

Preguntas:

¿Los textos sencillos garantizan el aprendizaje?

\begin{tabular}{|c|c|c|c|c|c|c|c|}
\hline $\begin{array}{c}\text { Primer } \\
\text { semestre }\end{array}$ & $\begin{array}{c}\text { Muy de } \\
\text { acuerdo }\end{array}$ & $\begin{array}{c}\text { De } \\
\text { acuerdo }\end{array}$ & $\begin{array}{c}\text { Parcial. de } \\
\text { acuerdo }\end{array}$ & $\begin{array}{c}\text { Parcial. en } \\
\text { desacuerdo }\end{array}$ & $\begin{array}{c}\text { En } \\
\text { desacuerdo }\end{array}$ & $\begin{array}{c}\text { Muy en } \\
\text { desacuerdo }\end{array}$ & $\%$ \\
\hline $\begin{array}{l}\text { Los textos } \\
\text { sencillos } \\
\text { garantizan el } \\
\text { aprendizaje }\end{array}$ & $11 \%$ & $36 \%$ & $37 \%$ & $10 \%$ & $4 \%$ & $3 \%$ & $100 \%$ \\
\hline
\end{tabular}

Tabla comparativa 1. Actitudes frente a la sencillez de los textos 


\begin{tabular}{|l|c|c|c|c|c|c|c|}
\hline $\begin{array}{c}\text { Quinto } \\
\text { año }\end{array}$ & $\begin{array}{c}\text { Muy de } \\
\text { acuerdo }\end{array}$ & $\begin{array}{c}\text { De } \\
\text { acuerdo }\end{array}$ & $\begin{array}{c}\text { Parcial. de } \\
\text { acuerdo }\end{array}$ & $\begin{array}{c}\text { Parcial. en } \\
\text { desacuerdo }\end{array}$ & $\begin{array}{c}\text { En } \\
\text { desacuerdo }\end{array}$ & $\begin{array}{c}\text { Muy en } \\
\text { desacuerdo }\end{array}$ & $\%$ \\
\hline $\begin{array}{l}\text { Los textos } \\
\text { sencillos } \\
\text { garantizan el } \\
\text { aprendizaje }\end{array}$ & $18 \%$ & $51 \%$ & $21 \%$ & $6 \%$ & $3 \%$ & $1 \%$ & $100 \%$ \\
\hline
\end{tabular}

Continuación Tabla comparativa 1. Actitudes frente a la sencillez de los textos

Se observa un incremento del quinto año con relación al primer semestre en torno a la percepción sobre los textos sencillos. Mientras un $47 \%$ se ubica en la zona del acuerdo (que incluye muy de acuerdo y de acuerdo) en el primer semestre, en el quinto año este porcentaje aumenta a $69 \%$. Se percibe una disminución del $20 \%$ en la zona del parcialmente de acuerdo y el desacuerdo. Y una disminución del 3\% en el desacuerdo. Llama la atención de que a pesar del avance en el proceso de formación, el estudiante pida del texto "sencillez". Dicha sencillez podría estar orientada hacia visiones instrumentales del aprendizaje o de todas formas responden a una percepción equivocada de lo que es "sencillo", ya que el texto presenta demandas que deben ser abordadas con base en las características del texto mismo. En ese sentido, según Cadena Castillo (2007) no se trata de que el texto sea o no fácil, es necesario ofrecerle al estudiante las estrategias necesarias para comprender los textos.

Al hacer el cruce con las respuestas al cuestionario abierto, se observa que en el grupo de quinto año, no se tiene claridad acerca de cuáles son los procesos que se deben seguir para emprender un proceso de lectura.

Se observa en estas respuestas que hay una especie de abandono al estudiante a su suerte. La lectura queda así subsumida como una expresión de voluntad, esfuerzo y dedicación del estudiante (ver tabla 1) como una tarea que él debe cumplir, y para hacerlo debe garantizar un ambiente adecuado que evite desconcentraciones y que le permita al estudiante emprender en solitario el tremendo esfuerzo de decodificación de la lectura (ver tabla 2 y 3 ). O como una búsqueda personal producto del dominio en un tema o del interés por profundizar en él (ver tabla 4). En general es poco el dominio que poseen de estrategias cognitivas, metacognitivas o discursivas que le permitan desenvolverse autónomamente en la lectura de un texto (ver tabla 5). Dicho desconocimiento 
¿Cómo cambian los conceptos acerca de la lectura y la escritura en la Facultad...

se debe en gran medida a que los docentes de las áreas específicas no han orientado a los estudiantes acerca de los propósitos de lectura, no les brindan estrategias para abordar la lectura de los textos y no derivan procesos de evaluación que permitan un abordaje discursivo del texto. Esto fundamentado en la idea de que el estudiante no sólo posee esos conocimientos, sino de que la lectura es responsabilidad exclusiva de ellos, idea que en los estudiantes de quinto año se encuentra arraigada.

\begin{tabular}{|c|c|c|}
\hline \multicolumn{2}{|c|}{$\begin{array}{c}\text { Si alguien le pidiera tres consejos para comprender } \\
\text { mejor lo que lee, ¿qué consejos le brindaría? }\end{array}$} \\
\hline \multirow{2}{*}{ Tipo } & Valoración & $\begin{array}{c}\text { Número } \\
\text { de ocurrencias }\end{array}$ \\
\hline \multirow{2}{*}{ Actitudinales } & Concentración & 28 \\
\cline { 2 - 3 } & Ganas & 9 \\
\cline { 2 - 3 } & Disposición & 3 \\
\cline { 2 - 3 } & Constancia & 2 \\
\hline \multirow{2}{*}{$\begin{array}{c}\text { "Concentración, gusto por la lectura, buena disposición” } \\
\text { "Releer, leer lo que gusta, meterse en la lectura" } \\
\text { "Concentración, imaginación, leer a gusto" }\end{array}$} \\
\hline
\end{tabular}

Tabla 1. Valoración de los condicionamientos intrínsecos del proceso lector

\begin{tabular}{|c|c|c|}
\hline \multicolumn{3}{|c|}{$\begin{array}{c}\text { Si alguien le pidiera tres consejos para comprender } \\
\text { mejor lo que lee, ¿qué consejos le brindaría? }\end{array}$} \\
\hline Tipo & Valoración & $\begin{array}{c}\text { Número } \\
\text { de ocurrencias }\end{array}$ \\
\hline Ambientales & Lugar apropiado & 16 \\
\hline $\begin{array}{l}\text { "Meterse en la lectura, buscar lugar tranquilo, sacar ideas principales" } \\
\text { "Concentración, entender lo leído, no leer cansado" } \\
\text { "Buscar sitio tranquilo, leer de corrido, hacer glosario" } \\
\text { "Concentración, buen ambiente, gusto" }\end{array}$ \\
\hline
\end{tabular}

Tabla 2. Valoración de los condicionamientos ambientales del proceso lector 


\begin{tabular}{|c|c|c|}
\hline \multicolumn{2}{|c|}{$\begin{array}{c}\text { Si alguien le pidiera tres consejos para comprender } \\
\text { mejor lo que lee, ¿qué consejos le brindaría? }\end{array}$} \\
\hline \multirow{2}{*}{ Tipo } & Valoración & $\begin{array}{c}\text { Número } \\
\text { de ocurrencias }\end{array}$ \\
\hline \multirow{2}{*}{ Decodificación } & Leer detenidamente & 16 \\
\cline { 2 - 3 } & Releer & 7 \\
\cline { 2 - 3 } & Puntuación & 3 \\
\hline \multirow{2}{*}{$\begin{array}{l}\text { "Leer despacio, usar puntuación, reflexionar lo leído" } \\
\text { "Buscar sitio tranquilo, leer de corrido, hacer glosario" } \\
\text { "Releer, leer lo que gusta, meterse en la lectura" } \\
\text { "Leer las letras desde la parte superior de las palabras, no devolverse y leer más } \\
\text { rápido" } \\
\text { "Concentración, no leer muchas páginas de seguido" }\end{array}$} \\
\hline
\end{tabular}

Tabla 3. La lectura como simple decodificación

\begin{tabular}{|c|c|c|}
\hline \multicolumn{2}{|c|}{$\begin{array}{c}\text { Si alguien le pidiera tres consejos para comprender } \\
\text { mejor lo que lee, ¿qué consejos le brindaría? }\end{array}$} \\
\hline \multirow{2}{*}{ Tipo } & Valoración & $\begin{array}{c}\text { Número } \\
\text { de ocurrencias }\end{array}$ \\
\hline \multirow{2}{*}{ Temáticas } & Apropiación & 3 \\
\cline { 2 - 3 } & Escogencia & 2 \\
\cline { 2 - 3 } & Profundización \\
\hline $\begin{array}{l}\text { Leer lo que más gusta, más conocimiento } \\
\text { Interés, concentración y que el tema sí le guste } \\
\text { Abrir la mente, leer como si le gustara mucho, hacer preguntas del texto } \\
\text { Releer, leer lo que gusta, meterse en la lectura }\end{array}$ \\
\hline
\end{tabular}

Tabla 4. La lectura como producto del interés temático 
¿Cómo cambian los conceptos acerca de la lectura y la escritura en la Facultad...

\begin{tabular}{|c|c|c|}
\hline \multicolumn{3}{|c|}{$\begin{array}{l}\text { Si alguien le pidiera tres consejos para comprender } \\
\text { mejor lo que lee, ¿qué consejos le brindaría? }\end{array}$} \\
\hline Tipo & Valoración & $\begin{array}{c}\text { Número } \\
\text { de ocurrencias }\end{array}$ \\
\hline \multirow{7}{*}{ Cognitivas } & Subrayar & 13 \\
\hline & Consultar & 5 \\
\hline & Formularse pregunta & 3 \\
\hline & argumentar & 2 \\
\hline & Borrador de lo leído & 2 \\
\hline & Sacar conclusiones & 2 \\
\hline & Sintetizar & 1 \\
\hline \multicolumn{3}{|c|}{$\begin{array}{l}\text { Hacer resumen y comparar con el texto } \\
\text { Identificar tipo de texto, ideas principales, sacar vocabulario } \\
\text { Concentrarse, hojear el texto, buscar significado a palabras } \\
{ }^{\star} \text { Leer y volver a leer, subrayar y analizar } \\
{ }^{\star} \text { Ideas principales, consultar vocabulario } \\
{ }^{\star} \text { Leer varias fuentes referentes al texto, concentrarse } \\
{ }^{\star} \text { Leer bien los títulos, resaltar, y sacar glosario }\end{array}$} \\
\hline
\end{tabular}

Tabla 5. Estrategias cognitivas y metacognitivas aplicadas por los estudiantes de quinto año

\begin{tabular}{|c|c|c|c|c|c|c|c|}
\hline $\begin{array}{c}\text { Primer } \\
\text { semestre }\end{array}$ & $\begin{array}{c}\text { Muy de } \\
\text { acuerdo }\end{array}$ & $\begin{array}{c}\text { De } \\
\text { acuerdo }\end{array}$ & $\begin{array}{c}\text { Parcial. de } \\
\text { acuerdo }\end{array}$ & $\begin{array}{c}\text { Parcial. en } \\
\text { desacuerdo }\end{array}$ & $\begin{array}{c}\text { En } \\
\text { desacuerdo }\end{array}$ & $\begin{array}{c}\text { Muy en } \\
\text { desacuerdo }\end{array}$ & $\%$ \\
\hline $\begin{array}{l}\text { La lectura en } \\
\text { la educación } \\
\text { superior es } \\
\text { una respon- } \\
\text { sabilidad } \\
\text { exclusiva del } \\
\text { estudiante. }\end{array}$ & $12 \%$ & $29 \%$ & $31 \%$ & $17 \%$ & $10 \%$ & $2 \%$ & $100 \%$ \\
\hline
\end{tabular}

Tabla comparativa 2. Actitudes frente a la lectura como responsabilidad exclusiva del estudiante 


\begin{tabular}{|l|c|c|c|c|c|c|c|}
\hline Quinto año & $\begin{array}{c}\text { Muy de } \\
\text { acuerdo }\end{array}$ & $\begin{array}{c}\text { De } \\
\text { acuerdo }\end{array}$ & $\begin{array}{c}\text { Parcial. de } \\
\text { acuerdo }\end{array}$ & $\begin{array}{c}\text { Parcial. en } \\
\text { desacuerdo }\end{array}$ & $\begin{array}{c}\text { En } \\
\text { desacuerdo }\end{array}$ & $\begin{array}{c}\text { Muy en } \\
\text { desacuerdo }\end{array}$ & $\%$ \\
\hline $\begin{array}{l}\text { La lectura en } \\
\text { la educación } \\
\text { superior es } \\
\text { una respon- } \\
\text { sabilidad } \\
\text { exclusiva del } \\
\text { estudiante. }\end{array}$ & $26 \%$ & $32 \%$ & $17 \%$ & $8 \%$ & $8 \%$ & $8 \%$ & $100 \%$ \\
\hline
\end{tabular}

Continuación Tabla comparativa 2. Actitudes frente a la lectura como responsabilidad exclusiva del estudiante

Se observa un acumulado de acuerdo del $41 \%$ en el primer semestre, porcentaje que se incrementa a un 58\% para el quinto año. Si se sumaran los porcentajes anteriores más el parcialmente de acuerdo en ambos grupos, se encontraría una similitud en los porcentajes: $72 \%$ para el primer semestre, $75 \%$ para el quinto año. Se nota en todo caso un incremento en el acuerdo y una tendencia al decrecimiento en el desacuerdo.

Sumado a lo anterior, se observa que los estudiantes en ese esfuerzo individual de la lectura, le brindan gran peso a los factores ambientales como base para mantener el interés y la motivación. Es cierto que la lectura exige un ambiente adecuado, pero muchas de las llamadas técnicas de estudio enfatizan en este aspecto, descuidando que la lectura es una relación interactiva en la cual el lector pone en consideración sus saberes, interroga al texto y aplica una serie de estrategias para extraer la mayor información. Dichas estrategias son variadas, pero en lo encontrado se centran mayoritariamente en el subrayado, lo cual, según Díaz Barriga (2002), corresponde a una recirculación de la información de tipo memorístico. Se nota poca actividad de procesamiento complejo mediante la elaboración de resúmenes. De igual forma, se evidencia poca frecuencia en establecer relaciones con los saberes previos, formularse preguntas de investigación, reconocer títulos, capítulos y estructura del texto. No hay evidencia de que se fijen propósitos de aprendizaje ni de que se cotejen con lo que el texto ofrece.

Hay pocos registros de la lectura como un acto de investigación y profundización. En la parte relacionada con la temática se observa un acercamiento a esta tendencia. La lectura intertextual se remite mayoritariamente a la búsqueda de palabras desconocidas en el diccionario. Esto que podría ser un acercamiento a una visión socio cultural de la 
¿Cómo cambian los conceptos acerca de la lectura y la escritura en la Facultad...

lectura, ya que acerca al campo conceptual de la disciplina mediante la elaboración de un glosario, podría también ser la evidencia de que el estudiante al leer no discrimina los conceptos esenciales de aquellos que obedecen a un registro más universal y que corresponden a los mínimos de comprensión que el estudiante debe dominar. De igual forma, no se observa ninguna alusión a la búsqueda de información en diccionarios especializados. Esta descripción se corrobora con el hallazgo de las siguientes afirmaciones:

\begin{tabular}{|c|c|c|c|c|c|c|c|}
\hline $\begin{array}{c}\text { Primer } \\
\text { semestre }\end{array}$ & $\begin{array}{c}\text { Muy de } \\
\text { acuerdo }\end{array}$ & $\begin{array}{c}\text { De } \\
\text { acuerdo }\end{array}$ & $\begin{array}{c}\text { Parcial. de } \\
\text { acuerdo }\end{array}$ & $\begin{array}{c}\text { Parcial. en } \\
\text { desacuerdo }\end{array}$ & $\begin{array}{c}\text { En } \\
\text { desacuerdo }\end{array}$ & $\begin{array}{c}\text { Muy en } \\
\text { desacuerdo }\end{array}$ & $\%$ \\
\hline $\begin{array}{l}\text { Si uno tiene } \\
\text { buena for- } \\
\text { mación lec- } \\
\text { tora desde el } \\
\text { bachillerato, } \\
\text { no tendrá } \\
\text { ninguna di- } \\
\text { ficultad para } \\
\text { leer en la } \\
\text { universidad. }\end{array}$ & $10 \%$ & $27 \%$ & $21 \%$ & $20 \%$ & $15 \%$ & $6 \%$ & $100 \%$ \\
\hline
\end{tabular}

\begin{tabular}{|c|c|c|c|c|c|c|c|}
\hline $\begin{array}{c}\text { Quinto } \\
\text { año }\end{array}$ & $\begin{array}{c}\text { Muy de } \\
\text { acuerdo }\end{array}$ & $\begin{array}{c}\text { De } \\
\text { acuerdo }\end{array}$ & $\begin{array}{c}\text { Parcial. de } \\
\text { acuerdo }\end{array}$ & $\begin{array}{c}\text { Parcial. en } \\
\text { desacuerdo }\end{array}$ & $\begin{array}{c}\text { En } \\
\text { desacuerdo }\end{array}$ & $\begin{array}{c}\text { Muy en } \\
\text { desacuerdo }\end{array}$ & $\%$ \\
\hline $\begin{array}{l}\text { Si uno tiene } \\
\text { buena for- } \\
\text { mación lec- } \\
\text { tora desde el } \\
\text { bachillerato, } \\
\text { no tendrá } \\
\text { ninguna di- } \\
\text { ficultad para } \\
\text { leer en la } \\
\text { universidad. }\end{array}$ & $36 \%$ & $29 \%$ & $18 \%$ & $10 \%$ & $4 \%$ & $3 \%$ & $100 \%$ \\
\hline
\end{tabular}

Tabla comparativa 3. Actitudes frente a la lectura como dominio generalizable

Se presenta una diferencia muy significativa del $28 \%$, un $65 \%$ de estudiantes del quinto año consideran que la formación en el bachillerato es indispensable y es la base para la lectura en la educación superior, y un $37 \%$ de estudiantes recién salidos del bachillerato piensan lo mismo. 
Llama la atención que la diferencia sea mayor en grados superiores. El nivel de desacuerdo en el quinto año es muy bajo. Sumando los tres niveles de desacuerdo, se llega a un $17 \%$, lo cual no es ni la mitad del porcentaje que contestó estar muy de acuerdo con esta afirmación.

Dicho resultado profundiza la idea de que el docente universitario no tiene la responsabilidad de enseñar a leer y a escribir al estudiante desde sus áreas. Se asume que el estudiante ya viene formado desde el bachillerato y que los cursos de nivelación ofrecidos en semestres iniciales son suficientes para suplir los requerimientos de formación en lectura. De esta forma se desconoce que la lectura es un acto discursivo mediado por los conceptos y formas de expresión propios de cada disciplina.

Este abandono conduce, entonces, a las prácticas de lectura impositiva, definidas como formas de controlar al estudiante más que como estrategia de inclusión en las prácticas disciplinares. De allí se deriva que el estudiante vea la dificultad como algo indeseable desde la lectura. Esto se analizó en la siguiente afirmación: se lee por placer, por lo tanto es necesario alejarse de los textos difíciles.

\begin{tabular}{|l|c|c|c|c|c|c|c|}
\hline $\begin{array}{c}\text { Primer } \\
\text { semestre }\end{array}$ & $\begin{array}{c}\text { Muy de } \\
\text { acuerdo }\end{array}$ & $\begin{array}{c}\text { De } \\
\text { acuerdo }\end{array}$ & $\begin{array}{c}\text { Parcial. de } \\
\text { acuerdo }\end{array}$ & $\begin{array}{c}\text { Parcial. en } \\
\text { desacuerdo }\end{array}$ & $\begin{array}{c}\text { En } \\
\text { desacuerdo }\end{array}$ & $\begin{array}{c}\text { Muy en } \\
\text { desacuerdo }\end{array}$ & $\%$ \\
\hline $\begin{array}{l}\text { Se lee por } \\
\text { placer, por } \\
\text { lo tanto es } \\
\text { necesario } \\
\text { alejarse de } \\
\text { los textos } \\
\text { difíciles. }\end{array}$ & $34 \%$ & $34 \%$ & $20 \%$ & $8 \%$ & $2 \%$ & $2 \%$ & $100 \%$ \\
\hline
\end{tabular}

\begin{tabular}{|l|c|c|c|c|c|c|c|}
\hline $\begin{array}{c}\text { Quinto } \\
\text { año }\end{array}$ & $\begin{array}{c}\text { Muy de } \\
\text { acuerdo }\end{array}$ & $\begin{array}{c}\text { De } \\
\text { acuerdo }\end{array}$ & $\begin{array}{c}\text { Parcial. de } \\
\text { acuerdo }\end{array}$ & $\begin{array}{c}\text { Parcial. en } \\
\text { desacuerdo }\end{array}$ & $\begin{array}{c}\text { En } \\
\text { desacuerdo }\end{array}$ & $\begin{array}{c}\text { Muy en } \\
\text { desacuerdo }\end{array}$ & $\%$ \\
\hline $\begin{array}{l}\text { Se lee por } \\
\text { placer, por } \\
\text { lo tanto es } \\
\text { necesario } \\
\text { alejarse de } \\
\text { los textos } \\
\text { difíciles. }\end{array}$ & $1 \%$ & $4 \%$ & $18 \%$ & $15 \%$ & $50 \%$ & $11 \%$ & $100 \%$ \\
\hline
\end{tabular}

Tabla comparativa 4. Actitudes frente a la lectura como acto de relajación 
¿Cómo cambian los conceptos acerca de la lectura y la escritura en la Facultad...

Se pasa de un $68 \%$ de estudiante que opinan que se lee por placer y que es necesario alejarse de los textos difíciles, en relación con estudiantes del quinto año que constituyen un $5 \%$ de quienes piensan lo mismo. Llama la atención que el quinto año presenta una escasa diferencia entre quienes están parcialmente de acuerdo y quienes están parcialmente en desacuerdo. Hay un incremento notable en los niveles de desacuerdo, pues se pasa de un $4 \%$ a un $61 \%$. El nivel de incremento en el desacuerdo es muy cercano al nivel de descenso en el acuerdo, pues el primero se incrementa en un 57\%, mientras el segundo decrece en un $63 \%$.

Dentro de la afirmación sometida a consideración queda una duda: no es claro si el estudiante al plantear el desacuerdo frente a la afirmación está dando a entender que no le huye a los textos difíciles, o está queriendo decir que cuando hay placer ningún texto es difícil o no se le huye a la dificultad de los textos.

Dentro de la interpretación de la encuesta abierta, es posible inclinarse por la segunda, pues se observa una gran tendencia a la lectura de textos literarios o con fines informativos, por encima de los textos académicos. A la pregunta ¿qué lees habitualmente?, respondieron:

\begin{tabular}{|c|c|c|c|}
\hline \multicolumn{3}{|c|}{ ¿Qué lees habitualmente? } & Cantidad \\
\hline \multirow{10}{*}{$\begin{array}{l}\text { Textos } \\
\text { académicos }\end{array}$} & \multirow{8}{*}{ Textos universitarios } & Textos de universidad & 6 \\
\hline & & $\begin{array}{l}\text { Lo necesario de la } \\
\text { universidad y trabajo }\end{array}$ & 3 \\
\hline & & Los textos como tareas & 3 \\
\hline & & Textos académicos & 3 \\
\hline & & Documentos & 3 \\
\hline & & $\begin{array}{c}\text { Sólo trabajos de la } \\
\text { universidad }\end{array}$ & 2 \\
\hline & & Contabilidad & 2 \\
\hline & & Total & 22 \\
\hline & Manuales & & 1 \\
\hline & $\begin{array}{l}\text { Textos } \\
\text { investigativos }\end{array}$ & & 1 \\
\hline
\end{tabular}

Tabla 6. Hábitos de lectura académica de los estudiantes de quinto año 


\begin{tabular}{|l|l|c|}
\hline \multicolumn{2}{|c|}{ ¿Qué lees habitualmente? } & Cantidad \\
\hline \multirow{3}{*}{$\begin{array}{l}\text { Textos } \\
\text { informativos }\end{array}$} & Periódico, revistas & 10 \\
\cline { 2 - 3 } & El periódico & 9 \\
\cline { 2 - 3 } & ${ }^{*}$ Periódicos, tutoriales y libros cortos & 2 \\
\cline { 2 - 3 } & Carteleras y textos pequeños & 1 \\
\hline & Total & $\mathbf{2 2}$ \\
\hline
\end{tabular}

\begin{tabular}{|l|l|c|}
\hline \multirow{2}{*}{ ¿Qué lees habitualmente? } & Cantidad \\
\hline \multirow{3}{*}{ Textos Literarios } & Gabriel García Márquez & 1 \\
\cline { 2 - 3 } & William Ospina & 1 \\
\cline { 2 - 3 } & Novelas & 29 \\
\cline { 2 - 3 } & Novelas, noticias & 9 \\
\cline { 2 - 3 } & Románticos y de fantasía & 1 \\
\hline \multirow{2}{*}{} & Libros de drama & 5 \\
\hline & Mitología griega & 3 \\
\hline & Cuentos & 1 \\
\hline & Novelas de suspenso & $\mathbf{7 4}$ \\
\hline
\end{tabular}

\begin{tabular}{|c|c|c|}
\hline \multicolumn{2}{|c|}{ ¿Qué lees habitualmente? } & Cantidad \\
\hline \multirow{4}{*}{$\begin{array}{l}\text { Textos de } \\
\text { superación } \\
\text { personal } \\
\text { y autoayuda }\end{array}$} & Superación personal & 23 \\
\hline & Literatura cristiana & 1 \\
\hline & Apreciación a la vida & 1 \\
\hline & Total & 25 \\
\hline
\end{tabular}

Tabla 7. Otros hábitos de lectura de los estudiantes de quinto año 
¿Cómo cambian los conceptos acerca de la lectura y la escritura en la Facultad...

Y a la pregunta de para qué lee usted: se encuentra la siguiente respuesta:

\begin{tabular}{|c|c|c|c|}
\hline \multicolumn{3}{|c|}{ ¿Para qué lee usted? } & Cantidad \\
\hline \multirow{22}{*}{ Conocimiento } & \multirow{13}{*}{$\begin{array}{l}\text { Aprendizaje en } \\
\text { sentido general }\end{array}$} & Para adquirir conocimiento & 30 \\
\hline & & Para conocer sobre algo & 8 \\
\hline & & Para culturizarme & 8 \\
\hline & & Aprender y conocer & 6 \\
\hline & & $\begin{array}{l}\text { Para aprender } \\
\text { y comprender nuevas cosas }\end{array}$ & 4 \\
\hline & & Ampliar cultura general & 4 \\
\hline & & Para aprender cosas nuevas & 4 \\
\hline & & Para agilizar la mente & 3 \\
\hline & & Aprender, conocer & 3 \\
\hline & & $\begin{array}{l}\text { Aprender y enriquecerme } \\
\text { de conocimiento }\end{array}$ & 2 \\
\hline & & Para enriquecerme & 1 \\
\hline & & Desarrollar la mente & 1 \\
\hline & & Total & 74 \\
\hline & \multirow{9}{*}{$\begin{array}{c}\text { Fortalecimiento } \\
\text { de la lectura y la } \\
\text { escritura }\end{array}$} & Para aclarar dudas de ortografía & 5 \\
\hline & & Para aprender vocabulario & 3 \\
\hline & & $\begin{array}{l}\text { Para poder expresarme } \\
\text { y escribir bien }\end{array}$ & 1 \\
\hline & & $\begin{array}{l}\text { Enriquecer vocabulario } \\
\text { y ortografía }\end{array}$ & 1 \\
\hline & & $\begin{array}{l}\text { Para mejorar la lectura, gramática, } \\
\text { letrarme más y por hobby. }\end{array}$ & 1 \\
\hline & & Mejorar capacidad lectora & 1 \\
\hline & & $\begin{array}{l}\text { Porque puedo mejorar la relación } \\
\text { entre escribir y hablar }\end{array}$ & 1 \\
\hline & & $\begin{array}{l}\text { Para mejorar la comprensión } \\
\text { de lectura }\end{array}$ & 1 \\
\hline & & Total & 14 \\
\hline
\end{tabular}

Tabla 8. Propósitos de lectura asociados al conocimiento 


\begin{tabular}{|l|l|c|}
\hline \multicolumn{1}{|c|}{ ¿Para qué lee usted? } & Cantidad \\
\hline \multirow{5}{*}{ Información } & Para estar informado y realizar mis labores & 9 \\
\cline { 2 - 3 } & Para informarme & 10 \\
\cline { 2 - 3 } & Para estar informado & 9 \\
\cline { 2 - 3 } & TOTAL & $\mathbf{2 8}$ \\
\hline \multirow{5}{*}{ Distracción } & Entretenerme & 3 \\
\cline { 2 - 3 } & Desestresarme, divertirme & 1 \\
\cline { 2 - 3 } & Distraerme & 2 \\
\cline { 2 - 3 } & Por diversión & 4 \\
\cline { 2 - 3 } & Para relajarme & 1 \\
\cline { 2 - 3 } & Aprovechar el tiempo libre & $\mathbf{1 3}$ \\
\cline { 2 - 3 } & TOTAL & 1 \\
\hline \multirow{5}{*}{ Formación } & Para ser intelectual & $\mathbf{2}$ \\
\cline { 2 - 3 } & Para aprender para la vida & 1 \\
\cline { 2 - 3 } & TOTAL & 2 \\
\hline
\end{tabular}

Tabla 9. Otros propósitos de lectura de los estudiantes de quinto año

Esto podría favorecer la interpretación de que el estudiante lee para aprender, pero como una imposición, como tarea, pero que esta labor de la lectura como aprendizaje no impacta significativamente sus actitudes personales frente a la lectura académica. Además si se observan las respuestas se nota que el aprendizaje se plantea en un sentido muy general, casi como un cliché surgido de la valoración cultural de la lectura. Desde el concepto de la persona ilustrada y culta, se acepta que la lectura contribuye en gran parte a la acumulación de conocimientos. Por ello, la lectura se entiende como una forma de enriquecerse, culturizarse, conocer (casi como un turista que se asoma) y aprender cosas nuevas. El fugaz sentido de la novedad se impone sobre la rigurosidad de aprendizaje sistemático que está inmerso en la lectura académica e investigativa. Se evidenciaría así una brecha muy común en las percepciones de lectura, aquella que desvincula el aprendizaje del placer y que percibe la lectura 
¿Cómo cambian los conceptos acerca de la lectura y la escritura en la Facultad...

como un acto de relajación, de escapismo. Hecho que aplicado además a la literatura, conduce a desaprovechar el potencial formativo y cognoscitivo de ésta.

\section{Escritura}

\section{¿La escritura es una forma de demostrar el conocimiento?}

\begin{tabular}{|c|c|c|c|c|c|c|c|}
\hline $\begin{array}{c}\text { Primer } \\
\text { semestre }\end{array}$ & $\begin{array}{c}\text { Muy de } \\
\text { acuerdo }\end{array}$ & $\begin{array}{c}\text { De } \\
\text { acuerdo }\end{array}$ & $\begin{array}{c}\text { Parcial. de } \\
\text { acuerdo }\end{array}$ & $\begin{array}{c}\text { Parcial. en } \\
\text { desacuerdo }\end{array}$ & $\begin{array}{c}\text { En } \\
\text { desacuerdo }\end{array}$ & $\begin{array}{c}\text { Muy en } \\
\text { desacuerdo }\end{array}$ & $\%$ \\
\hline $\begin{array}{l}\text { La escritura } \\
\text { es una forma } \\
\text { de demos- } \\
\text { trar el } \\
\text { conocimiento. }\end{array}$ & $12 \%$ & $29 \%$ & $31 \%$ & $17 \%$ & $10 \%$ & $2 \%$ & $100 \%$ \\
\hline
\end{tabular}

\begin{tabular}{|l|c|c|c|c|c|c|c|}
\hline Quinto año & $\begin{array}{c}\text { Muy de } \\
\text { acuerdo }\end{array}$ & $\begin{array}{c}\text { De } \\
\text { acuerdo }\end{array}$ & $\begin{array}{c}\text { Parcial. de } \\
\text { acuerdo }\end{array}$ & $\begin{array}{c}\text { Parcial. en } \\
\text { desacuerdo }\end{array}$ & $\begin{array}{c}\text { En } \\
\text { desacuerdo }\end{array}$ & $\begin{array}{c}\text { Muy en } \\
\text { desacuerdo }\end{array}$ & $\%$ \\
\hline $\begin{array}{l}\text { La escritura } \\
\text { es una forma } \\
\text { de demos- } \\
\text { trar el } \\
\text { conocimiento. }\end{array}$ & $18 \%$ & $36 \%$ & $29 \%$ & $4 \%$ & $10 \%$ & $3 \%$ & $100 \%$ \\
\hline
\end{tabular}

Tabla comparativa 5. La escritura como reflejo del conocimiento

En general no se observa una gran diferencia entre ambos grupos. La zona de acuerdo pasa de un $41 \%$ a un $54 \%$, diferencia de un $13 \%$ que se mantiene aún sumando la zona del parcialmente de acuerdo. Es injusto atribuir esta preeminencia al hecho de desconocer la escritura como una forma de construir conocimiento. Por esta razón se hace una pregunta en este último sentido, para indagar si los estudiantes ven la escritura como simple expresión de lo sabido o si le dan un papel más trascendente en relación con la posibilidad de brindarle forma al saber. 


\section{¿Gracias a la escritura puedo aprender un tema?}

\begin{tabular}{|c|c|c|c|c|c|c|c|}
\hline $\begin{array}{c}\text { Primer } \\
\text { semestre }\end{array}$ & $\begin{array}{c}\text { Muy de } \\
\text { acuerdo }\end{array}$ & $\begin{array}{c}\text { De } \\
\text { acuerdo }\end{array}$ & $\begin{array}{c}\text { Parcial. de } \\
\text { acuerdo }\end{array}$ & $\begin{array}{c}\text { Parcial. en } \\
\text { desacuerdo }\end{array}$ & $\begin{array}{c}\text { En } \\
\text { desacuerdo }\end{array}$ & $\begin{array}{c}\text { Muy en } \\
\text { desacuerdo }\end{array}$ & $\%$ \\
\hline $\begin{array}{l}\text { Gracias a } \\
\text { la escritu- } \\
\text { ra puedo } \\
\text { aprender } \\
\text { un tema. }\end{array}$ & $12 \%$ & $33 \%$ & $34 \%$ & $13 \%$ & $6 \%$ & $1 \%$ & $100 \%$ \\
\hline
\end{tabular}

\begin{tabular}{|c|c|c|c|c|c|c|c|}
\hline $\begin{array}{c}\text { Quinto } \\
\text { año }\end{array}$ & $\begin{array}{c}\text { Muy de } \\
\text { acuerdo }\end{array}$ & $\begin{array}{c}\text { De } \\
\text { acuerdo }\end{array}$ & $\begin{array}{c}\text { Parcial. de } \\
\text { acuerdo }\end{array}$ & $\begin{array}{c}\text { Parcial. en } \\
\text { desacuerdo }\end{array}$ & $\begin{array}{c}\text { En } \\
\text { desacuerdo }\end{array}$ & $\begin{array}{c}\text { Muy en } \\
\text { desacuerdo }\end{array}$ & $\%$ \\
\hline $\begin{array}{c}\text { Gracias a } \\
\text { la escritu- } \\
\text { ra puedo } \\
\text { aprender } \\
\text { un tema. }\end{array}$ & $15 \%$ & $29 \%$ & $38 \%$ & $11 \%$ & $6 \%$ & $1 \%$ & $100 \%$ \\
\hline
\end{tabular}

Tabla comparativa 6. La escritura como forma de construir conocimiento

Si nos atenemos a los hallazgos teóricos, es posible afirmar que se presenta una contradicción entre estas dos respuestas, pues al percibir la escritura como un reflejo del conocimiento, se afecta la posibilidad de entenderla como un medio para construirlo. Desde la teoría consultada se encuentra que la representación social que percibe la escritura como un reflejo del conocimiento, recalca en la evaluación del texto como un producto inmutable.

De esta forma, los textos se convierten en una especie de espejo del propio pensamiento, exigen el correlato de la situación compartida para poder interpretarse, pues el escritor (y su habitual lector, el docente) asumen como trasparentes muchos de los implícitos que pululan en él. Se genera así el modelo de escritura que Scardamalia y Bereiter (citados por Carlino, 2004), denominan "decir el conocimiento", en oposición al modelo "trasformar el conocimiento".

En el modelo "decir el conocimiento", quien escribe, "recupera de su memoria lo que sabe sobre un tema y lo expresa en el papel" (Carlino, 2004, p. 323). Esta forma de escritura es casi un acto ensimismado de extracción de saberes, en el cual la escritura se valida a partir de las necesidades del escritor más que del lector. $\mathrm{Al}$ respecto se agregan dos preguntas formuladas: 
¿Cómo cambian los conceptos acerca de la lectura y la escritura en la Facultad...

1. ¿Un texto debe escribirse de tal manera que a cualquier lector le interese?

2. ¿Si uno al escribir no tiene en cuenta su posible lector, el texto no estará bien escrito?

\begin{tabular}{|l|c|c|c|c|c|c|c|}
\hline \multicolumn{1}{|c|}{$\begin{array}{c}\text { Primer } \\
\text { semestre }\end{array}$} & $\begin{array}{c}\text { Muy de } \\
\text { acuerdo }\end{array}$ & $\begin{array}{c}\text { De } \\
\text { acuerdo }\end{array}$ & $\begin{array}{c}\text { Parcial. de } \\
\text { acuerdo }\end{array}$ & $\begin{array}{c}\text { Parcial. en } \\
\text { desacuerdo }\end{array}$ & $\begin{array}{c}\text { En } \\
\text { desacuerdo }\end{array}$ & $\begin{array}{c}\text { Muy en } \\
\text { desacuerdo }\end{array}$ & $\%$ \\
\hline $\begin{array}{l}\text { Un texto } \\
\text { debe escri- } \\
\text { birse de tal } \\
\text { manera que } \\
\text { a cualquier } \\
\text { lector le } \\
\text { interese. }\end{array}$ & $14 \%$ & $26 \%$ & $29 \%$ & $19 \%$ & $11 \%$ & $1 \%$ & $100 \%$ \\
\hline
\end{tabular}

\begin{tabular}{|l|c|c|c|c|c|c|c|}
\hline $\begin{array}{c}\text { Primer } \\
\text { semestre }\end{array}$ & $\begin{array}{c}\text { Muy de } \\
\text { acuerdo }\end{array}$ & $\begin{array}{c}\text { De } \\
\text { acuerdo }\end{array}$ & $\begin{array}{c}\text { Parcial. de } \\
\text { acuerdo }\end{array}$ & $\begin{array}{c}\text { Parcial. en } \\
\text { desacuerdo }\end{array}$ & $\begin{array}{c}\text { En } \\
\text { desacuerdo }\end{array}$ & $\begin{array}{c}\text { Muy en } \\
\text { desacuerdo }\end{array}$ & $\%$ \\
\hline $\begin{array}{l}\text { Si uno al } \\
\text { escribir } \\
\text { no tiene } \\
\text { en cuenta } \\
\text { su posible } \\
\text { lector, el } \\
\text { texto no } \\
\text { estará bien } \\
\text { escrito. }\end{array}$ & $4 \%$ & $21 \%$ & $31 \%$ & $26 \%$ & $15 \%$ & $3 \%$ & $100 \%$ \\
\hline
\end{tabular}

Tabla comparativa 7. Actitudes frente a la perspectiva retórica en estudiantes de primer semestre

Llama la atención que estas dos preguntas que nos ubican en extremos opuestos de la actitud, tengan niveles de acuerdo similares. Esto podría interpretarse de dos formas: primero, que las afirmaciones inducen la respuesta por brindarle al estudiante ideas que aunque él no había pensado, tienen sentido para él y al carecer de unas prácticas concretas y unas teorías que le permitan tomar posición, opta por inclinarse al acuerdo en ambas. Segundo, puede ser que aunque el estudiante reconozca el papel del interlocutor en la escritura, no se hace una imagen clara de él, y enfatiza su presencia al pensar sólo los aspectos de corrección y claridad, dejando de lado aspectos retóricos fundamentales. 
Se observa las afirmaciones en quinto año:

1. Un texto debe escribirse de tal manera que a cualquier lector le interese.

2. Si uno al escribir no tiene en cuenta su posible lector, el texto no estará bien escrito.

\begin{tabular}{|l|c|c|c|c|c|c|c|}
\hline \multicolumn{1}{|c|}{$\begin{array}{c}\text { Quinto } \\
\text { año }\end{array}$} & $\begin{array}{c}\text { Muy de } \\
\text { acuerdo }\end{array}$ & $\begin{array}{c}\text { De } \\
\text { acuerdo }\end{array}$ & $\begin{array}{c}\text { Parcial. de } \\
\text { acuerdo }\end{array}$ & $\begin{array}{c}\text { Parcial. en } \\
\text { desacuerdo }\end{array}$ & $\begin{array}{c}\text { En } \\
\text { desacuerdo }\end{array}$ & $\begin{array}{c}\text { Muy en } \\
\text { desacuerdo }\end{array}$ & $\%$ \\
\hline $\begin{array}{l}\text { Un texto } \\
\text { debe escri- } \\
\text { birse de tal } \\
\text { manera que } \\
\text { a cualquier } \\
\text { lector le } \\
\text { interese. }\end{array}$ & $24 \%$ & $44 \%$ & $20 \%$ & $6 \%$ & $6 \%$ & $1 \%$ & $100 \%$ \\
\hline
\end{tabular}

\begin{tabular}{|l|c|c|c|c|c|c|c|}
\hline \multicolumn{1}{|c|}{$\begin{array}{c}\text { Quinto } \\
\text { año }\end{array}$} & $\begin{array}{c}\text { Muy de } \\
\text { acuerdo }\end{array}$ & $\begin{array}{c}\text { De } \\
\text { acuerdo }\end{array}$ & $\begin{array}{c}\text { Parcial. de } \\
\text { acuerdo }\end{array}$ & $\begin{array}{c}\text { Parcial. en } \\
\text { desacuerdo }\end{array}$ & $\begin{array}{c}\text { En } \\
\text { desacuerdo }\end{array}$ & $\begin{array}{c}\text { Muy en } \\
\text { desacuerdo }\end{array}$ & $\%$ \\
\hline $\begin{array}{l}\text { Si uno al } \\
\text { escribir } \\
\text { no tiene } \\
\text { en cuenta } \\
\text { su posible } \\
\text { lector, el } \\
\text { texto no } \\
\text { estará bien } \\
\text { escrito. }\end{array}$ & $17 \%$ & $35 \%$ & $25 \%$ & $15 \%$ & $7 \%$ & $1 \%$ & $100 \%$ \\
\hline
\end{tabular}

Tabla comparativa 8. Actitudes frente a la perspectiva retórica en estudiantes de quinto año

Se observa exactamente el mismo fenómeno en ambas respuestas. Muy diferente a la percepción de la escritura como construcción del conocimiento, que interpreta el acto escritural como un proceso de ajuste permanente mediado por las exigencias comunicativas que surgen. En este orden de ideas, la escritura se comprende como un proceso sujeto a ajustes y revisiones permanentes, a lectura entre pares, a definición de propósitos de escritura y esencialmente a la delimitación de un posible lector con el fin de efectuar los ajustes retóricos necesarios. Por eso, la mejor forma de indagar por las actitudes en la relación entre saber y escritura, pueden ser rastreadas en dos preguntas que se formularon en la encuesta abierta: ¿para usted que significa escribir bien?, y ¿cuáles son las tareas que usted realiza cuando escribe? 


\begin{tabular}{|c|c|c|c|}
\hline \multicolumn{3}{|c|}{ ¿Para usted qué significa escribir bien? } & Cantidad \\
\hline \multirow{7}{*}{$\begin{array}{c}\text { La escritura } \\
\text { como } \\
\text { traducción del } \\
\text { pensamiento }\end{array}$} & \multicolumn{2}{|c|}{ Expresar lo que sé } & 1 \\
\hline & \multicolumn{2}{|c|}{ Plasmar lo que se piensa } & 8 \\
\hline & \multicolumn{2}{|c|}{$\begin{array}{l}\text { Acomodar ideas y conceptos en forma escrita } \\
\text { claramente }\end{array}$} & 1 \\
\hline & \multicolumn{2}{|c|}{ Escribir con conocimiento } & 2 \\
\hline & \multicolumn{2}{|c|}{ Ser capaz de plasmar en el papel las ideas } & 1 \\
\hline & \multicolumn{2}{|c|}{ Transmitir pensamientos al papel } & 2 \\
\hline & \multicolumn{2}{|l|}{ Total } & 15 \\
\hline \multirow{20}{*}{$\begin{array}{l}\text { La valoración } \\
\text { de la escritura } \\
\text { desde la correc- } \\
\text { ción gramatical }\end{array}$} & \multirow{9}{*}{ Ortografía } & Tener buena ortografia & 11 \\
\hline & & Buena ortografía y coherencia & 10 \\
\hline & & $\begin{array}{l}\text { Tener buena ortografía, escribir } \\
\text { en forma coherente }\end{array}$ & 6 \\
\hline & & Es aplicar las normas ortográficas & 3 \\
\hline & & $\begin{array}{l}\text { Para conocer los conectores de } \\
\text { ortografía }\end{array}$ & 1 \\
\hline & & $\begin{array}{l}\text { Saber lo que escribo, usar palabras } \\
\text { técnicas y buena ortografía }\end{array}$ & 1 \\
\hline & & Orden lógico y ortografía & 1 \\
\hline & & Con buena ortografía y coherencia & 1 \\
\hline & & Total & 34 \\
\hline & Gramática & Buena gramática & 3 \\
\hline & & *Saber manejar puntuación & 2 \\
\hline & & Total & 5 \\
\hline & & & \\
\hline & \multirow{7}{*}{$\begin{array}{l}\text { Adecuación y } \\
\text { Lógica }\end{array}$} & ${ }^{*}$ Buena ortografía y coherencia & 0 \\
\hline & & $\begin{array}{l}\text { Tener coherencia con lo que se } \\
\text { escribe }\end{array}$ & 10 \\
\hline & & $\begin{array}{l}\text { Que el escrito tenga sentido y sea } \\
\text { claro }\end{array}$ & 4 \\
\hline & & Brindar ideas claras de un texto & 3 \\
\hline & & $\begin{array}{l}\text { Es escribir con ideas claras } \\
\text { y coherencia, puntuación y } \\
\text { ortografía }\end{array}$ & 2 \\
\hline & & Que todo tenga conexión & 1 \\
\hline & & Total & 20 \\
\hline
\end{tabular}

Tabla 10. Perspectivas de escritura entre los estudiantes de quinto año 
En el numeral 1 de la tabla 9, la escritura como traducción del pensamiento, se evidencia lo que Gilberto Fregoso denomina content approach: un enfoque que asume que el dominio de los conceptos fundamentales garantiza el dominio de la escritura en ese campo disciplinar. "La escritura a través del currículo, el énfasis en tareas académicas o proyectos y los reportes sobre la habilidad promedio del aprendizaje de la redacción en todos los campos disciplinares son la base teórico-práctica de esta actitud preocupada por el fondo y desdeñosa de cuestiones gramaticales, funcionales o de proceso" (Fregoso, 2010, p. sp.)

En el numeral 2 de la tabla, la valoración de la escritura desde la corrección gramatical, se observa el Model's approach, el cual se centra en el modelo del texto "la organización, secuencia y cohesión del texto como elementos lógicos, junto con el manejo gramatical configuran un deber ser para la calidad del producto" (Fregoso, 2010, p. sp). Este modelo se fundamenta en los estudios de la gramática y la lingüística de corte prescriptivo, parte de la enseñanza de conceptos gramaticales, para de allí devenir en la práctica de ejercicios aplicativos que finalmente buscan su materialización en la escritura de textos. La evaluación del texto tiene el enfoque gramatical (Cassany, 1990).

Ambos tienen el efecto adverso de ignorar los procesos de construcción, reelaboración y ajuste, derivados de un enfoque procesual que además de implicar una revisión y ajuste permanente de los textos, incluye su producción en el contexto de una situación comunicativa real. En dicho enfoque se "redacta identificando al receptor, la función comunicativa del mensaje, el contexto de la interlocución y el tipo de composición; sobre todo, confían en la efectividad de su mensaje" (Fregoso, 2010). Se rescata el gusto por la escritura, deteniéndose más en el proceso que en el producto final. El objetivo es rescatar aquellas prácticas de los escritores exitosos para transferirlas a aquellos lectores novatos (Fregoso, 2010). La escritura es un proceso que se debe dominar y el docente debe acompañar al estudiante en ese proceso (Cassany, 1990). La presencia de este enfoque en los estudiantes de quinto año, se evidencia fundamentalmente en la conciencia de un lector modelo, lo que Paula Carlino denomina perspectiva retórica (2004). 
¿Cómo cambian los conceptos acerca de la lectura y la escritura en la Facultad...

\begin{tabular}{|l|l|c|}
\hline \multicolumn{2}{|c|}{ ¿Para usted qué significa escribir bien? } & Cantidad \\
\hline & Hacer que el lector pueda comprender & 7 \\
\cline { 2 - 3 } & Hacerme comprender de forma escrita & 6 \\
\cline { 2 - 3 } & Plasmar palabras sencillas para apasionar al lector & 3 \\
\cline { 2 - 3 } Perspectiva & $\begin{array}{l}\text { Es que la persona que me está leyendo entienda de } \\
\text { qué se trata }\end{array}$ & 2 \\
\cline { 2 - 3 } & Darica a entender claramente lo que se escribe & 2 \\
\cline { 2 - 3 } & $\begin{array}{l}\text { Representación clara y concreta sin usar términos } \\
\text { enredados }\end{array}$ & 2 \\
\cline { 2 - 3 } & Que sean claras para quien lo lee & 1 \\
\cline { 2 - 3 } & Transmitir el mensaje de la mejor forma & 1 \\
\cline { 2 - 3 } & $\begin{array}{l}\text { Anotar lo que comprendo entendible para mí y } \\
\text { otros lectores }\end{array}$ & $\mathbf{2 6}$ \\
\cline { 2 - 3 } & Hacer que el lector llegue al mismo fin & 1 \\
\cline { 2 - 3 } & Total & 2 \\
\hline
\end{tabular}

Tabla 11. La escasa perspectiva retórica entre los estudiantes de quinto año

Lo cual está por debajo de la percepción gramatical (numeral 2, tabla 9) y por encima de la percepción enfocada en el contenido (numeral 1, tabla 9).

Con respecto a las tareas que se emprenden para escribir, las siguientes tablas resumen las respuestas de los estudiantes:

\begin{tabular}{|l|l|c|}
\hline \multicolumn{2}{|c|}{ ¿Qué tareas realiza usted al momento de escribir? } & Cantidad \\
\hline \multirow{4}{*}{ Proceso } & Organizar mis ideas y argumentar & 5 \\
\cline { 2 - 3 } & Plantear ideas & 4 \\
\cline { 2 - 3 } & Realizo borrador y voy seleccionando ideas & 2 \\
\cline { 2 - 3 } & Pensar coherentemente, plasmar y corregir & 2 \\
\cline { 2 - 3 } & $\begin{array}{l}\text { Conocer el tema a investigar, plantear y organizar } \\
\text { ideas }\end{array}$ & 1 \\
\cline { 2 - 3 } & Atención, organizar ideas y corrección & 1 \\
\cline { 2 - 3 } & Total & $\mathbf{1 5}$ \\
\hline
\end{tabular}

Tabla 12. La escritura como proceso en los estudiantes de quinto año 
Se agrupan estas respuestas con base en un criterio básico: la conciencia que tiene el estudiante de que la escritura tiene un momento de planificación en el cual se define el lector, el propósito, las ideas que se tienen, un momento de elaboración en el cual se organizan las ideas y se redacta el primer borrador; y un momento de evaluación en el cual se entrega a pares y se hacen ajustes. Estas respuestas, aunque incompletas, se acercan a una conciencia de proceso.

\begin{tabular}{|l|l|c|}
\hline \multicolumn{2}{|c|}{ ¿Qué tareas realiza usted al momento de escribir? } & Cantidad \\
\hline \multirow{4}{*}{$\begin{array}{l}\text { Relación } \\
\text { lectura y } \\
\text { escritura }\end{array}$} & Investigar para tener una idea & 4 \\
\cline { 2 - 3 } & Leer y analizar & 4 \\
\cline { 2 - 3 } & Leer mucho & 4 \\
\cline { 2 - 3 } & Leer, comprender, pensar y escribir & 2 \\
\cline { 2 - 3 } & Leer y entender & 1 \\
\cline { 2 - 3 } & Informarme sobre el tema & 1 \\
\cline { 2 - 3 } & Leo & 1 \\
\cline { 2 - 3 } & Releer & $\mathbf{1 9}$ \\
\cline { 2 - 3 } & Plasmar lo que comprendí de una lectura & 1 \\
\cline { 2 - 3 } & Total & 1 \\
\hline
\end{tabular}

Tabla 13. Respuestas que establecen un vínculo entre escritura y lectura en estudiantes de quinto año

En estas respuestas se presenta una expresión de la importancia que tiene la lectura como medio para llegar a la escritura. Sin embargo, se reitera la clásica relación lectoescritura en detrimento de la percepción de scripto-lectura (Polo, Bustamante \& Avendaño, 2010), la cual cuestiona la creencia extendida de que para escribir bien es necesario leer primero. Creencia que interpreta la lectura como acto meramente acumulativo. La escritura en esta percepción es una habilidad mucho más fácil de desarrollar que la lectura, pues en esta última es necesario captar implícitos, recuperar saberes lejanos al lector y reconstruir el contexto. En tanto quien escribe se hace dueño de la situación, instaura el contexto y decide cuáles saberes incluir y cuáles fortalecer de acuerdo con el propósito del texto (Polo, Bustamante \& Avendaño, 2010). 
¿Cómo cambian los conceptos acerca de la lectura y la escritura en la Facultad...

La lectura desde las necesidades de escritura adquiere mayor sentido, en tanto se lee para llenar los vacíos de conocimiento, para fortalecer la argumentación o para interpretar realidades cuyo sentido escapa a nuestro marco de referencia. Como afirma Tynjala (2001), "hay la tendencia a pensar que primero debe leerse y adquirir conocimiento; y que sólo cuando se tenga eso, es hora de escribir. El movimiento de escribir para aprender reversa la situación" (Citado por Polo, Bustamante, \& Avendaño, 2010, p. 138). Sustentados en dicha perspectiva teórica es preocupante que haya tan escaso número de registros en ese sentido, ya que el estrecho vínculo entre lectura y escritura se expresa en las prácticas didácticas que interpretan la escritura como una forma de profundizar en los saberes y no sólo como una labor de control.

\begin{tabular}{|l|l|c|}
\hline \multicolumn{2}{|c|}{ ¿Qué tareas realiza usted al momento de escribir? } & Cantidad \\
\hline \multirow{4}{*}{$\begin{array}{l}\text { La escritura } \\
\text { como } \\
\text { práctica }\end{array}$} & Redactar & Borradores \\
\cline { 2 - 3 } & Redacto & 5 \\
\cline { 2 - 3 } & Corregir & 1 \\
\cline { 2 - 3 } & Trabajo, frases, escritos breves & 1 \\
\cline { 2 - 3 } & Total & 1 \\
\hline
\end{tabular}

Tabla 14. La lectura como práctica permanente en estudiantes de quinto año

Estas respuestas que parecen tautológicas, esconden gran riqueza. A escribir se aprende escribiendo. Escribir es una práctica permanente que por sus características demanda una revisión constante de lo que se sabe. No es desdeñable ninguna práctica escritural en tanto implique una revisión de saberes, un ajuste de la expresión de acuerdo con las exigencias comunicativas y una permanente reelaboración, en tanto esa práctica tenga sentido dentro de unos procesos comunicativos. Convertir a los estudiantes en escritores trasforma el rol de aprendices pasivos. Muchas veces el único que aprende es el docente, por el hecho de ser él quien debe preparar el saber y trans- 
formarlo para hacerlo comprensible. Este movimiento es similar al operado en la escritura y debería ser estimulado entre los estudiantes (Carlino, 2005).

La información contenida en las tablas 11, 12 y 13 esbozan lo que puede interpretarse como la conciencia escritural basada en procesos, sin embargo, no se hace explícita esa conciencia ni se reconocen los procesos involucrados en la escritura, lo cual permite inferir que no existe una valoración muy precisa en relación con la escritura como forma de aprender, sobre todo si constatamos la gran cantidad de respuestas que apuntaron a la escritura como traducción del conocimiento.

\begin{tabular}{|c|c|c|}
\hline \multicolumn{2}{|c|}{ ¿Qué tareas realiza usted al momento de escribir? } & Cantidad \\
\hline \multirow{16}{*}{$\begin{array}{l}\text { Énfasis en el } \\
\text { contenido }\end{array}$} & Razono & 12 \\
\hline & Analizo & 9 \\
\hline & Ideas claras & 5 \\
\hline & Analizar, sintetizar y concluir & 3 \\
\hline & Pensar, escribir y reflexionar & 3 \\
\hline & Pensar y analizar el tema & 2 \\
\hline & Usar la imaginación & 2 \\
\hline & Concentrarme, aclarar ideas & 1 \\
\hline & Agilizar la mente & 1 \\
\hline & $\begin{array}{l}\text { Entender en lo posible lo que mi mente relaciona, } \\
\text { y que con palabras digo }\end{array}$ & 1 \\
\hline & Pienso & 1 \\
\hline & Ejercitar la mano y abrir la mente & 1 \\
\hline & Soltar la mano, memorizar & 1 \\
\hline & Dejo fluir mis ideas & 1 \\
\hline & Concentración en la idea & 1 \\
\hline & Total & 44 \\
\hline
\end{tabular}

Tabla 15. Tareas que enfatizan en el dominio previo del contenido 
¿Cómo cambian los conceptos acerca de la lectura y la escritura en la Facultad...

Se observa la aceptación de la escritura como un proceso que involucra procesos mentales, sin embargo, se percibe que se presenta una especie de mirada extractiva del saber. La escritura aparece como un reflejo del conocimiento, como una catarsis y liberación del saber. Es como si hubiera que estar al acecho, a la espera de que la palabra encuentre el momento oportuno para brindarle forma al pensamiento. De allí se deriva la tendencia a aplazar el momento para escribir, de esperar a que las ideas estén claras, ignorando que la escritura, en gran medida, contribuye a clarificar ese saber. Cada aproximación al conocimiento demanda un proceso escritural que debe ser preservado y aprovechado. La diferencia radica en que existe un momento privado para la escritura, el de recoger las dudas, evidenciar las búsquedas; y un momento público, el de sustentar y difundir las ideas (Carlino, 2005).

Adicional a estas respuestas se encontraron algunas que no alcanzan a configurar una tendencia, pero que denotan el desconocimiento de las tareas implicadas en la escritura: ambientales (buena postura, estar sola, busco un lugar tranquilo), aquellas que abiertamente dicen desconocer esas tareas (no sé, no responde, ninguna en especial, nada), y otras difíciles de catalogar (no complicarse, decido).

Cuando escribo un texto, ¿hago una elaboración final para detectar sólo errores ortográficos y de puntuación?

Se presenta una diferencia del $8 \%$ en el nivel de acuerdo y se observa que los alumnos hacen la revisión desde el punto de vista gramatical y ortográfico.

Entre la zona media del acuerdo y parcialmente de acuerdo se está hablando casi de un $65 \%$ de alumnos del quinto año que hacen la revisión con fines ortográficos y de puntuación. Si bien, Daniel Casany (1990) afirma que lo último que se revisa en un texto es la ortografía y la gramática, porque cognitivamente uno no puede procesas las dos cosas; también es cierto que Paula Carlyno (2004) plantea que la revisión superficial del texto es uno de los defectos y debilidades que existen en el proceso de escritura universitaria y constituye una representación nociva para el fortalecimiento de la escritura. Esta revisión superficial pretende la verificación de lo ya dicho, desperdiciando así la oportunidad de efectuar cambios sus- 
tanciales en el último proceso de revisión. No se revisa la estructura, la información, el enfoque de la escritura en relación con la intención; lo único que se revisa es la cohesión, aspecto de vínculo entre párrafos, ortografía y gramática. Esto debido al desconocimiento retórico del texto.

La escritura se interpreta como una elaboración definitiva, que al responder a lo ya sabido es impermeable a cualquier trasformación radical, so pena de tener que reelaborar los conceptos que se tienen arraigados en la conciencia del escritor novato. Se desperdicia así el potencial dialéctico de la escritura, pues no se somete a cuestión el pensamiento por considerar el texto como un producto cristalizado y garante de la verdad.

\begin{tabular}{|l|c|c|c|c|c|c|c|}
\hline \multicolumn{1}{|c|}{$\begin{array}{c}\text { Primer } \\
\text { semestre }\end{array}$} & $\begin{array}{c}\text { Muy de } \\
\text { acuerdo }\end{array}$ & $\begin{array}{c}\text { De } \\
\text { acuerdo }\end{array}$ & $\begin{array}{c}\text { Parcial. de } \\
\text { acuerdo }\end{array}$ & $\begin{array}{c}\text { Parcial. en } \\
\text { desacuerdo }\end{array}$ & $\begin{array}{c}\text { En } \\
\text { desacuerdo }\end{array}$ & $\begin{array}{c}\text { Muy en } \\
\text { desacuerdo }\end{array}$ & $\%$ \\
\hline $\begin{array}{l}\text { Cuando } \\
\text { escribo } \\
\text { un texto, } \\
\text { hago una } \\
\text { elaboración } \\
\text { final para } \\
\text { detectar } \\
\text { sólo errores } \\
\text { ortográficos } \\
\text { yde pun- } \\
\text { tuación. }\end{array}$ & $14 \%$ & $26 \%$ & $29 \%$ & $19 \%$ & $11 \%$ & $1 \%$ & $100 \%$ \\
\hline
\end{tabular}

\begin{tabular}{|l|c|c|c|c|c|c|c|}
\hline $\begin{array}{c}\text { Quinto } \\
\text { año }\end{array}$ & $\begin{array}{c}\text { Muy de } \\
\text { acuerdo }\end{array}$ & $\begin{array}{c}\text { De } \\
\text { acuerdo }\end{array}$ & $\begin{array}{c}\text { Parcial. de } \\
\text { acuerdo }\end{array}$ & $\begin{array}{c}\text { Parcial. en } \\
\text { desacuerdo }\end{array}$ & $\begin{array}{c}\text { En } \\
\text { desacuerdo }\end{array}$ & $\begin{array}{c}\text { Muy en } \\
\text { desacuerdo }\end{array}$ & $\%$ \\
\hline $\begin{array}{l}\text { Cuando } \\
\text { escribo } \\
\text { un texto, } \\
\text { hago una } \\
\text { elaboración } \\
\text { final para } \\
\text { detectar } \\
\text { sólo errores } \\
\text { ortográficos } \\
\text { y de pun- } \\
\text { tuación. }\end{array}$ & $6 \%$ & $42 \%$ & $23 \%$ & $17 \%$ & $11 \%$ & $1 \%$ & $100 \%$ \\
\hline
\end{tabular}

Tabla comparativa 9. Actitudes frente a la revisión textual en estudiantes de quinto año 
¿Cómo cambian los conceptos acerca de la lectura y la escritura en la Facultad...

\section{Conclusiones}

El estudio al centrarse en las perspectivas de los estudiantes permite rastrear el impacto formativo que las prácticas de lectura y escritura han tenido en ellos. En general se observa que las actitudes de los estudiantes de la Facultad de Contaduría Pública de la Universidad Autónoma Latinoamericana, reafirman las creencias que ven la lectura como un dominio generalizable, y por lo tanto deposita en el bachillerato la responsabilidad de formar en lectura y escritura. Esto reitera la orfandad lectora del estudiante, quien ve la lectura académica como una exigencia externa a sus intereses de formación.

De igual forma, no se observa valoración de la escritura como forma para construir conocimiento, ya que se continúa interpretando ésta como un acto extractivo del saber, como trasmisión del conocimiento que ya se tiene. La escritura desde esta perspectiva se convierte en una prueba más y, por lo tanto, se enfatiza en el resultado ignorando el proceso.

Queda pendiente efectuar la descripción entre los docentes, con el fin de rastrear algunas didácticas y estrategias de evaluación de la lectura y la escritura. De esta forma, no sólo se comprenderá cómo estas prácticas están vinculadas o no a las actitudes de los estudiantes, sino cómo repercuten en la calidad de sus procesos de lectura y escritura.

\section{Bibliografía}

Araya Umaña, S. (2002). Las representaciones sociales: ejes teóricos para su discusión (Primera Edición). (F. L. Sociales, Ed.) San José, Costa Rica.

Bocca, A. M., \& Vasconcelo, N. B. (2008). Algunas reflexiones acerca de las pràcticas y representaciones sociales en estudiantes universitarios: la escritura acadèmica. (U. D. Caldas, Ed.) Revista Enunciación (13), 20-28.

Cadena Castillo, S., Narváez Cardona, E., \& Chacón, M. M. (2007). Comprensión de textos escritos académicos y tareas escritas en las asignaturas del área profesional: concepciones de maestros universitarios. (Universidad del Valle, Ed.). Lenguaje, 35 (1), 81-118.

Calderón, D. I. (2001). Sobre textos académicos. (Universidad de Caldas, Ed.). Revista Enunciación, 6, 35-43. 
CARLINo, P. (2004). El proceso de escritura académica: cuatro problemas de la enseñanza universitaria. (Universidad de Los Andes, Ed.). Educere, 8 (26), 321-327.

Carlino, P. (2005b). Enseñar no sólo exponiendo: enseñar a exponer en la universidad. (Universidad de Pampa, Ed.). Revista educación, lenguaje y sociedad, 3 (3), 207-229.

CARLINO, P. (2007). Escribir, leer y aprender en la unviersidad: una introducción a la alfabetización académica (Tercera Edición ed.). Buenos Aires: Fondo de Cultura Económica de Argentina.

Cassany, D. (1990). Enfoques didácticos para la enseñanza de la expresión escrita. (F. I. Aprendizaje, Ed.). Comunicación, lenguaje y educación, 6, 63-80.

Cuevas Mejía, J. J. (2009). La lecto-escrtura: por un acontecer en el lenguaje para pensar a la contabilidad -un ensayo-. (P. U. Javeriana, Ed.). Ábaco Contaduría, 1 (1 y 2), 45-47.

Fregoso, G. (enero de 2010). Cuatro debates en el seno de la alfabetización académica. Recuperado el 20 de mayo de 2010, de Revista Cuadernos de Educación y Desarrollo: http://www.eumed.net/rev/ced/11/gfp.htm

GonzÁlez Pinzón, B. J. (2007). Experiencia de alfabetización académica en la Universidad Sergio Arboleda de Colombia. Primer Encuentro Nacional sobre políticas institucionales para el desarrollo de la lectura y la escritura en la Educación Superior (pág. 9). Bogotá: REDLEES.

Hernández Sampieri, R., Fernández Collado, C., \& Baptista lucio, M. (2012). Metodología de la Investigación (Quinta Edición ed.). México, México: Mac Graw-Hill.

Lacon de Lucía, N. \& Ortega de Hocevar, L. (2008). Cognición, metacogniciòn y escritura. (Universidad de Valparaiso, Ed.). Signos, 41 (67), 231255.

Molano B., L. \& López, G. E. (2007). Concepciones de profesores y estudiantes sobre la escritura académica en la Universidad Icesi. (Universidad del Valle, Ed.). Revista Lenguaje, 35 (1), 119-146.

Nigro, P. (2006). Leer y escribir en la universidad: propuestas de articulación con la escuela media. (Universidad de La Sabana, Ed.). Educación y educadores, 9 (2), 119-127.

Padilla, C., Douglas de Sirgo, S., \& López, E. A. (2010). Competencias argumentativas en la alfabetización académica. (U. d. Valencia, \& D. e. http:// 
¿Cómo cambian los conceptos acerca de la lectura y la escritura en la Facultad...

ojs.uv.es/index.php/attic/article/view/177/207, Edits.). Atic: revista d'innovación educativa (4), 12.

Polo Figueroa, N., Bustamante, A. L., \& Avendaño Pantoja, A. (2010). Fundamentos teóricos y pedagógicos para la escritura: una aproximación en respuesta a un diagnóstico. (Universidad Sergio Arboleda, Ed.). Santa Marta, Colombia.

Rojas Rojas, W. (2008). Congoja por una educación contable fútil. (Universidad de Antioquia, Ed.) Contaduría, 52, 259-274.

VÁsquez, A. (2008). La producción de textos académicos a partir de fuentes múltiples y aprendizaje en la universidad: exigencias de la tarea, dificultades de los estudiantes. En E. Narváez Cardona, S. Cadena Castillo, \& U. A. Occidente (Ed.). Los desafíos de la lectura y la escritura en la educación superior: caminos posibles. (págs. 21-52). Cali.

\section{Gustavo Alberto Ruiz Rojas}

gustavoruizrojas@gmail.com

Licenciado en Español y Literatura. Candidato a Magíster en Educación. Docente de la Facultad de Contaduría Pública de la Universidad Autónoma Latinoamericana de Medellín. Es autor en revistas académicas especializadas en temas de educación, lectura y escritura.

\section{Yuliana Arcila Arcila}

yuli.2103@hotmail.com

Estudiante de la Facultad Contaduría Pública de la Universidad Autónoma Latinoamericana. Estudiante vinculada al semillero Lexema de la Facultad de Contaduría de la Universidad Autónoma Latinoamericana. 